\title{
IDENTIFIKASI KANDUNGAN UNSUR-UNSUR VARIETAS SERBUK KOPI DENGAN TEKNIK LASER INDUCED SHOCK WAVE PLASMA SPECTROSCOPY
}

\author{
Rani Septiani ${ }^{1, a)}$, Mangasi A. Marpaung ${ }^{1}$, Maria M. Suliyanti ${ }^{2}$ \\ ${ }^{1}$ Jurusan Fisika, FMIPA Universitas Negeri Jakarta Jl. Pemuda No 10, Jakarta 13220. \\ ${ }^{2}$ Pusat Penelitian Fisika-LIPI, Kawasan Puspiptek Serpong Tangerang Selatan 15314. \\ Email: ${ }^{a)}$ raniseptiani219@gmail.com
}

\begin{abstract}
Abstrak
Telah dilakukan penelitian untuk mengidentifikasi kandungan unsur- unsur varietas kopi dengan teknik Laser Induced Shock Wave Plasma Spectroscopy (LISPS). Varietas kopi yang digunakan adalah kopi luwak, kopi jawa dan kopi toraja. Ketiga sampel kopi semula berbentuk serbuk dan diberi perlakuan awal dengan dibentuk pellet agar serbuk kopi menjadi padat. Sampel pellet kopi diletakkan dalam sebuah ruang vakum yang bisa diatur tekanan udaranya. Agar dihasilkan emisi plasma, sampel pellet kopi ditembak oleh laser Nd:YAG (1064 nm) dengan variasi energi $12 \mathrm{~mJ}$ dan $45 \mathrm{~mJ}$. Untuk setiap variasi energi dilakukan variasi tekanan udara yaitu 5, 15 dan 35 torr. Emisi plasma yang dihasilkan ditangkap oleh spektrometer dan ditransmisikan ke monitor. Gambar spektrum emisi ditampilkan di monitor. Hasil penelitian menunjukkan bahwa teknik ini bisa digunakan untuk mengidentifikasi kandungan unsur-unsur kopi dan memberikan hasil analisa yang cepat dan real time. Untuk energi terendah $12 \mathrm{~mJ}$ dan $45 \mathrm{~mJ}$ garis spektrumnya sudah terlihat cukup tajam. Elemen yang dikandung ketiga varietas kopi yaitu $\mathrm{Ca}(\mathrm{Kalsium}), \mathrm{K}(\mathrm{Kalium}), \mathrm{Mg}$ (Magnesium) dan H(Hidrogen). Hasil eksperimen menunjukkan bahwa spektrum emisi paling tajam terlihat pada (45 mJ, 5torr). Dan dari ketiga sampel, kopi luwak memiliki spektrum paling tajam.
\end{abstract}

Kata Kunci : Laser Induced Shock Wave Plasma Spectroscopy (LISPS), Teknik Ablasi Laser, Identifikasi Unsur Kopi

\begin{abstract}
Research to identify the elements of varieties of coffee powder with Laser Induced Shock Wave Plasma Spectroscopy LISPS have done. Varieties of coffees used are civet coffee, java coffee and toraja coffee. The samples were originally in powder and those made into pellets. Sample were put in a vacuum chamber that can be set the air pressure. Laser Nd:YAG(1064 nm) irradiated sample and produce plasma with energy variation $12 \mathrm{~mJ}$ and $45 \mathrm{~mJ}$. For each energy variation is given pressure variation 5 , 15 and 35 Torr. Plasma emission recorded by spectrometer and spectrum emission shown on the monitor. The result of research show that this method can be used for identify the elements of coffee powder and gives a fast and real time analysis. Spectrum emission already look good at $12 \mathrm{~mJ}$ and 45 $\mathrm{mJ}$. Elements of the three varieties of coffee are Ca (calcium), $\mathrm{K}$ (Potassium), $\mathrm{Mg}$ ( Magnesium) and $\mathrm{H}$ (Hydrogen). The result of this research showed that the best spectrum emission shown at (45 $\mathrm{mJ}, 5$ Torr), and the best spectrum emission among three samples of coffe is civet coffee.
\end{abstract}

Keywords: Laser Induced Shock Wave Plasma Spectroscopy (LISPS), Laser Ablation Technique, Identify the elements of coffee. 


\section{PENDAHULUAN}

Dalam bidang material, sebuah material terdiri tiga bagian yaitu padat, cair dan gas. Serbuk merupakan bagian dari zat padat, bahan serbuk baik yang kasar maupun halus, merupakan bahan dasar yang banyak dijumpai di industri kimia, fisika, farmasi dan industri lainnya. Berbagai bahan serbuk kimia murni dicampur dengan berbagai komposisi campuran dan komposisi campuran tersebut akan menentukan kualitas hasil akhir produk tersebut [8].

Salah satu produk dengan bahan serbuk yang sangat populer di dunia adalah Kopi. Berdasarkan keragaman indikasi geografisnya, Indonesia menjadi negara ketiga sebagai penghasil kopi terbanyak di dunia. Pemanfaatannya berupa biji kopi, biji kopi ini disangrai dan dihaluskan menjadi bahan serbuk. Menurut survei looplife, ada tujuh varietas kopi Indonesia yang sangat diminati di Indonesia dan mendunia yaitu kopi luwak, kopi jawa, kopi toraja, kopi sumatera, kopi bali, kopi lanang dan kopi wamena. Tiga diantaranya yaitu kopi luwak, kopi toraja dan kopi jawa yang akan digunakan dalam penelitian ini. Untuk menikmati ketiga kopi ini, kini bisa ditemukan dengan mudah karena sudah banyak industri kopi yang memproduksi kopi instan yang kemudian dijual dipasaran. Analisis komposisi dan sifat kimia suatu bahan sangat diperlukan dalam proses industri. Berbagai penelitian untuk menganalisa komposisi dan sifat kimia dalam suatu bahan sudah banyak dilakukan. Metode analisa sifat kimia serbuk kopi pernah dilakukan sebelumnya, metode yang digunakan yaitu dengan metode kimia. Data yang diperoleh berupa kadar air, kadar lemak dan kadar kafein untuk tiga varietas kopi [6]. Pada tahun 2005, Laboratorium FAO di Laos pernah melakukan penelitian untuk mengetahui unsur utama yang menyusun bagian tanaman kopi. Hasil penelitian menunjukkan bahwa ada 6 unsur utama yang menyusun bagian tanaman kopi.

Penelitian terakhir telah diperkenalkan sebuah metode yang tidak memerlukan perlakuan awal sampel yang rumit dalam tekniknya. Teknik ini sangat tepat terutama untuk analisa elemen berdasarkan pada emisi atomik dari plasma laser hasil pembangkitan dengan memfokuskan laser pada permukaan sampel. Metode ini disebut Laser Atomic Emission Spectrochemical Analysis (LAESA). LAESA terdiri dari dua teknik yaitu Laser Induced Breakdown Spectroscopy (LIBS) dan Laser Induced Shock Wave Plasma Spectroscopy (LISPS). LIBS merupakan metode LAESA yang menggunakan gas lingkungan dengan tekanan tinggi sedangkan LISPS menggunakan gas lingkungan dengan tekanan rendah. Beberapa analisis kandungan unsur suatu material dengan menggunakan metode LAESA sudah pernah dilakukan sebelumnya dengan metode LIBS dimana sampel yang digunakan yaitu kalium bromide dan pati. [4]. Sebelumnya juga pernah dilakukan Studi penelitian tentang aplikasi laser untuk analisa unsur dalam hard fossil dengan mengunakan LISPS [14].

Analisis kandungan unsur kopi dengan menggunakan teknik LISPS belum pernah dilakukan sebelumnya. Oleh karena itu, pada paper ini akan digunakan teknik LISPS untuk analisis kandungan unsur dari tiga varietas sampel kopi.

\section{METODOLOGI PENELITIAN}

Pada eksperimen ini varietas kopi yang digunakan adalah kopi luwak, kopi jawa dan kopi toraja. Ketiga sampel kopi semula berbentuk serbuk dan diberi perlakuan awal dengan dibentuk pellet agar serbuk kopi menjadi padat. Berikut tahap pembuatan sampel pellet kopi:

1. Membuat perekat dengan mencampur serbuk PVA dan Aqua B-des.

2. Menuangkan empat takaran serbuk kopi dalam sebuah wadah kecil.

3. Menambahkan perekat sekitar $1 / 4$ sendok spatula ke dalam kopi dan mengaduknya sampai rata.

4. Jika serbuk kopi dan perekat sudah tercampur rata, sampel kopi siap di buat pellet dengan alat pellet.

5. Jika sampel kopi sudah berbentuk pellet, sampel siap digunakan untuk eksperimen.

Untuk analisa unsur kopi digunakan laser pulsa Nd:YAG $1064 \mathrm{~nm}$ dengan energi yang diatur pada $12 \mathrm{~mJ}$ dan $45 \mathrm{~mJ}$. Berkas laser difokuskan dengan lensa pemfokus ( $\mathrm{f}=100 \mathrm{~mm}$ ) melalui jendela quartz ke permukaan sampel. Sampel pellet kopi ditempatkan pada chamber yang terbuat dari logam berukuran (11x11x25 cm3), yang dapat divakumkan dengan pompa vakum dan dapat diisi gas sesuai dengan tekanan yang diinginkan. Aliran gas dalam ruang vakum diatur oleh needle valve dan tekanan dalam ruang vakum dimonitor dan diukur dengan digital pirani meter. Variasi tekanan yang 
digunakan untuk setiap variasi energi adalah 5, 15 dan 35 torr. Set-up eksperimen analisa unsur tiga varietas sampel kopi ditunjukkan pada Gambar 1.

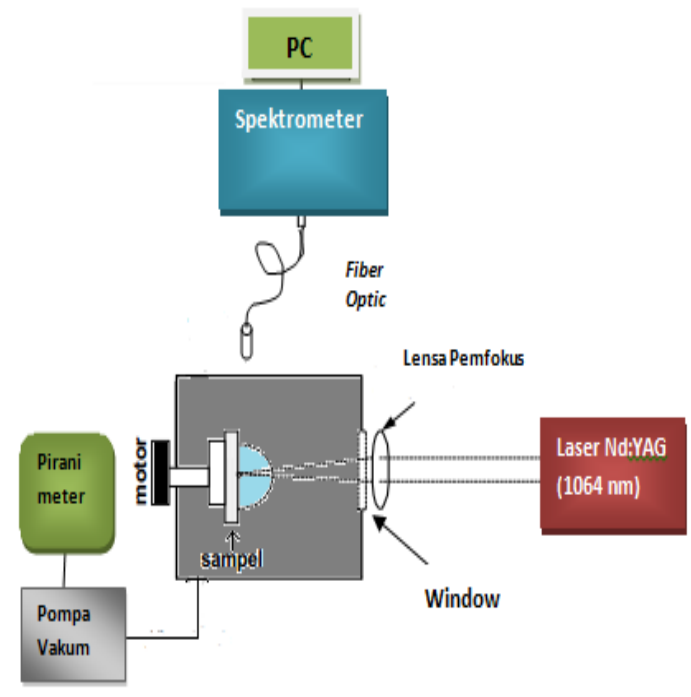

Gambar 1. Set Up Eksperimen

Cahaya plasma dideteksi oleh fiber optik dan ditransmisikan ke spektrometer yang telah dihubungkan dengan komputer dan akan diperoleh spektrum hubungan panjang gelombang dan intensitas yang ditampilkan pada layar komputer. Data spektrum emisi disimpan dengan format txt dan diinput ke program matlab untuk dibuat grafik dan dideteksi kandungan unsurnya.

\section{HASIL DAN PEMBAHASAN}

Pada penelitian ini, digunakan laser pulsa dengan daya tinggi. Jenis laser yang digunakan adalah laser Nd:YAG dengan panjang gelombang $1064 \mathrm{~nm}$ untuk diiradiasi kearah sampel kopi yang telah dibentuk pellet dengan tekanan gas dan energi yang divariasikan. Iradiasi laser difokuskan pada sampel, sehingga interaksi laser dengan bahan akan mengevaporasi sebagian kecil dari sampel, evaporasi (penguapan) ini merupakan perubahan fase dari material padat menjadi gas dengan temperatur tinggi, gas inilah yang merupakan plasma [10]. Cahaya plasma yang dihasilkan ditransmisikan menggunakan fiber optik ke spektrometer dan akan diperoleh spektrum emisi hubungan panjang gelombang dan intensitas yang ditampilkan pada layar komputer.

Gambar 2,3 dan 4 menunjukkan spektrum emisi ketiga sampel kopi pada kondisi tekanan udara yang divariasikan yaitu 5,15 dan 35 torr. Dari gambar terlihat bahwa semakin kecil tekanan udara yang diberikan maka spektrum emisi terlihat lebih bagus hal ini dikarenakan pada dasarnya prinsip kerja LISPS bekerja pada tekanan gas rendah. Jika kerapatan gas penyangga semakin kecil maka plasma yang mengembang menekan gas sekitarnya dengan mudah sehingga plasma merambat dengan cepat dan saat tereksitasi akan terlihat emisinya dan spectrum emisi yang dihasilkan lebih bagus [12]. 


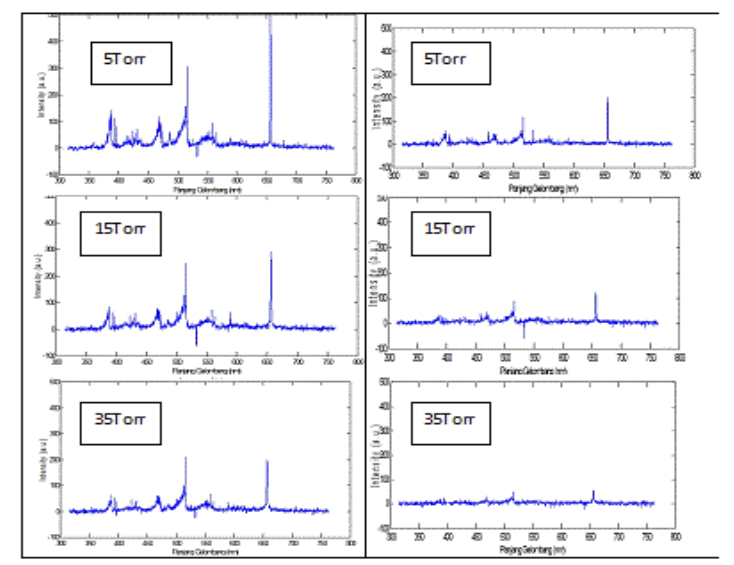

Gambar 2. Spektrum emisi Kopi luwak pada kondisi tiga variasi tekanan udara, kiri: energi (45 mJ), kanan: energi (12 mJ).

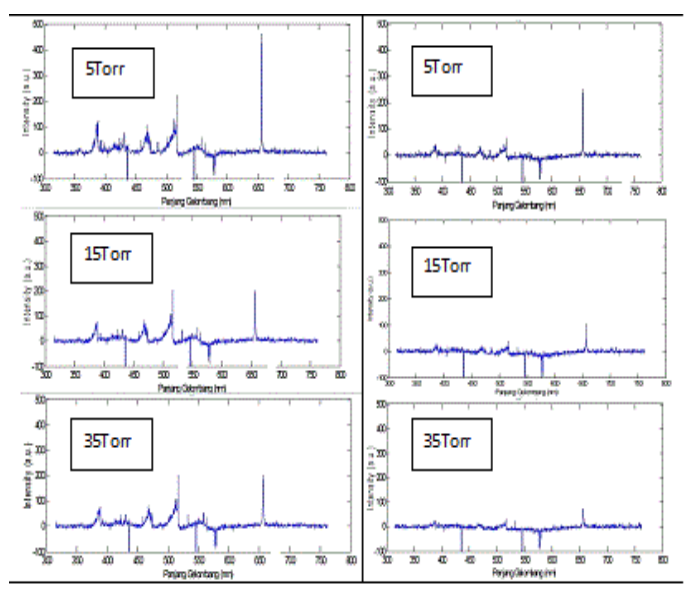

Gambar 3. Spektrum emisi Kopi jawa pada kondisi tiga variasi tekanan udara, kiri: energi (45 mJ), kanan: energi (12 mJ).

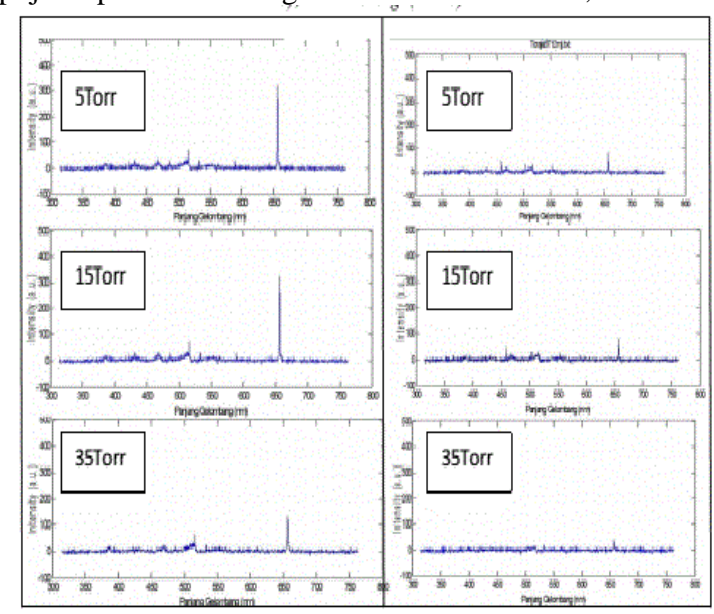

Gambar 4. Spektrum emisi Kopi Toraja pada kondisi tiga variasi tekanan udara, kiri: energi (45 mJ), kanan: energi (12 $\mathrm{mJ})$.

Perubahan energi yang diberikan juga berpengaruh terhadap spektrum emisinya. Dari gambar 2,3 dan 4 Spektrum yang paling bagus ditunjukkan oleh energi $45 \mathrm{~mJ}$. Pada prinsipnya laser memiliki ambang batas energi yang dipompakan, jadi dalam penggunaannya harus mempertimbangkan batas ambangnya. Jika energi yang berikan terlalu besar maka sampel akan lebih cepat rusak dan akan memperpendek usia penggunaannya laser. Sebaliknya, jika energi yang diberikan terlalu kecil maka emisi yang dihasilkan tidak akan cukup atau kurang bagus. Oleh karena itu, diperlukan optimasi 
batas minium energi yang dipompakan (lasing threshold), sehingga berkas laser yang dihasilkan cukup signifikan dengan umur pemakaian yang panjang. Maka dapat disimpulkan dari ketiga gambar, spektrum emisi yang paling bagus terlihat pada energi $45 \mathrm{~mJ}$ dan tekanan udara 5 Torr.

Pada Gambar 5 disajikan hasil eksperimen untuk karakterisasi ketiga sampel kopi berupa spektrum emisi pada daerah panjang gelombang 300-800 $\mathrm{nm}$. Spektrum emisi yang ditunjukkan pada gambar 5 merupakan spektrum emisi paling tajam dari ketiga sampel kopi (45mJ,5torr). Spektrum emisi ketiga sampel menunjukkan bahwa kopi luwak memiliki spektrum yang paling tajam dibandingkan dengan kopi toraja dan jawa,meskipun antara kopi jawa dan kopi luwak perbedaan spektrumnya tidak signifikan. Ketiga sampel kopi memiliki kandungan unsur yang sama yaitu, K $(388,342 \mathrm{~nm}), \mathrm{K}(465,938 \mathrm{~nm}), \mathrm{Mg}(516,732 \mathrm{~nm})$ dan H $(656,285 \mathrm{~nm})$.
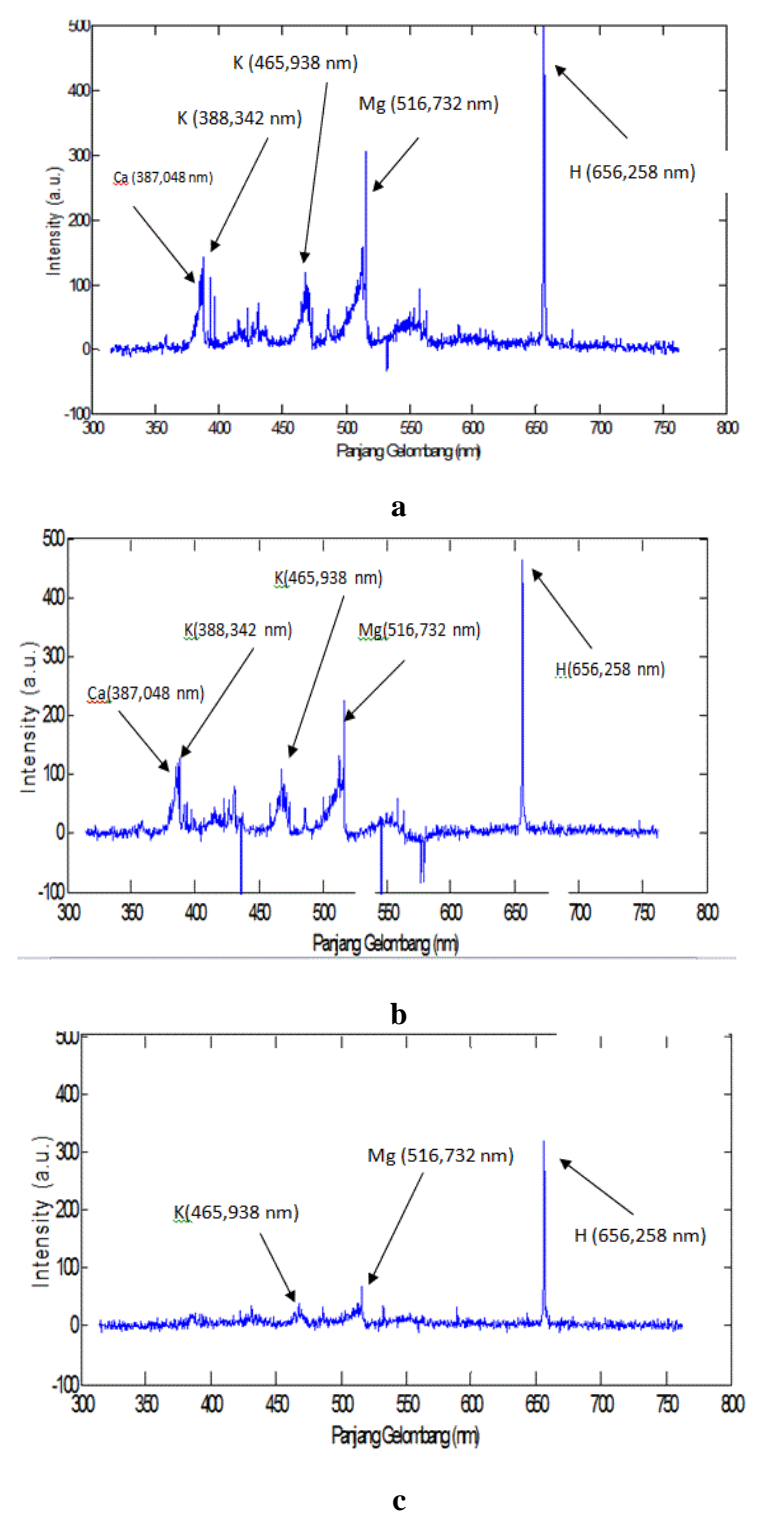

Gambar 5. Spektrum emisi tiga sampel kopi (45mJ,5torr) a.) Spektrum emisi kopi luwak b.) Spektrum emisi kopi jawa c.) Spektrum emisi kopi toraja

Kandungan unsur $\mathrm{Ca}(387,048 \mathrm{~nm})$ pada kopi luwak dan kopi jawa terlihat cukup jelas. Sedangkan, pada kopi toraja kandungan unsur Ca sebenarnya terdeteksi pada program matlab hanya saja peaknya sangat kecil. Sehingga dapat disimpulkan bahwa kadar kandungan unsur $\mathrm{Ca}, \mathrm{K} \mathrm{Mg}$ dan $\mathrm{H}$ pada kopi luwak paling tinggi dibandingkan dengan kopi jawa dan kopi toraja. 


\section{SIMPULAN}

Hasil penelitian menunjukkan bahwa teknik ini bisa digunakan untuk mengidentifikasi kandungan unsur-unsur kopi dan memberikan hasil analisa yang cepat dan real time. Untuk energi terendah 12 $\mathrm{mJ}$ dan $45 \mathrm{~mJ}$ garis spektrumnya sudah terlihat cukup tajam. Elemen yang dikandung ketiga varietas kopi yaitu $\mathrm{Ca}($ Kalsium), $\mathrm{K}($ Kalium), $\mathrm{Mg}$ (Magnesium) dan $\mathrm{H}($ Hidrogen). Hasil eksperimen menunjukkan bahwa spektrum emisi paling tajam terlihat pada (45 mJ, 5torr). Dan dari ketiga sampel, kopi luwak memiliki spektrum paling tajam dan memiliki kadar kandungan unsur $\mathrm{Ca}, \mathrm{K}, \mathrm{Mg}$ dan $\mathrm{H}$ paling tinggi.

\section{UCAPAN TERIMAKASIH}

1. Dr.Mangasi Alion Marpaung, M.Si. selaku pembimbing dari jurusan Fisika UNJ.

2. Dr.Maria Margaretha Suliyanti, M.T. selaku pembimbing dari Pusat Penelitian LIPI Fisika.

3. Teman-teman Fisika Murni UNJ 2012.

\section{DAFTAR ACUAN}

[1] Anshori, Jamaludin.(2005).Spektrometri Serapan Atom.Bandung:Universitas Padjadjaran.

[2] Fransisca.,dkk.(2009).Spektroskopi Atomik dan Molekuler.Depok:Universitas Indonesia.

[3] Fuferti,Megah.,dkk.(2013). Perbandingan Karakteristik Fisis Kopi Luwak (Civet coffee) dan Kopi Biasa Jenis Arabika.Pillar of Physics, pp.68-75.

[4] Gondal, M.A., Hussain, T., Yamani, Z.H., Baig, M.A. (2007). The Role of Various Binding Materials for Trace Elemental Analysis of Powder Samples Using Laser Induced Breakdown Spectroscopy, Talanta, 72, 642.

[5] Gultom,Vina.(2015).Laser Induced Shock Wave Plasma Spectroscopy dan Aplikasinya. Jurnal Optik dan Laser.

[6] Hayati,Rita.,dkk.(2012). Sifat Kimia dan Evaluasi Sensori Bubuk Kopi Arabika .Jurnal Floratek, hal 66-75.

[7] Khumaeni,A.,dkk.(2011).Rapid Analysis of Tiny Amount of Powder Samples Using Transversely Excited Atmospheric CO2 Laser-induced He Gas Plasma with the Aid of HighVacuum Silicon Grease as a Binder on Metal Subtarget. Applied Spectroscopy, 65, 236-241.

[8] Madjid, Syahrun Nur .(2012). Studi Analisis Serbuk dengan Teknik Krim Silikon Menggunakan Plasma Tekanan Tinggi yang Diinduksi oleh Laser Nd: YAG .Jurnal Rekayasa Kimia dan Lingkungan, Vol. 9, No. 2, hal. $74-80$.

[9] Marpaung,Mangasi.(2013).Pembangkitan Plasma dengan Laser Pulsa Daya Tinggi .Jurnal Seminar Nasional Fisika UNJ.Jakarta:Universitas Negeri Jakarta.

[10] Marpaung,Mangasi.,dkk.(1995). Analisis Spektrokimia dengan Spektroskopi Plasma Gelombang Kejut oleh Laser dengan Sumber Radiasi Laser Nitrogen . Laporan Penelitian. Jakarta: Universitas Negeri Jakarta.

[11] Muchiar.(2007).Pembuatan Model Laser Nd-YAG Gelombang Kontinyu Daya Rendah. Jurnal Fisika dan Aplikasinya,Vol 3, No. 2.

[12] Pardede,Marincan.(1998).Efek Penguapan Selektif pada Plasma Gelombang Kejut Iradiasi Laser. Tesis Program Studi Elektronika dan Aplikasi Laser .Jakarta:Universitas Indonesia.

[13] Setiabudi,Wahyu . (1998). Interaksi Plasma Laser dengan Material Padat dan Aplikasinya untuk Spektrokimia .Jakarta:Dewan Riset Nasional. 
[14] Suliyanti,M.M.(2010). Aplikasi Laser dalam Analisa Unsur dengan Teknik Pembangkitan Plasma dan Metode Pelapisan. Jurnal Himpunan Fisika Indonesia,Vol. 10, No. 1. 
Spektra: Jurnal Fisika dan Aplikasinya http://doi.org/10.21009/SPEKTRA
Volume 2 Nomor 1 , April 2017
p-ISSN: 2541-3384

e-ISSN: 2541-3392 